\title{
OPTIMASI PENJADWALAN WAKTU KERJA MENGGUNAKAN INTEGER PROGRAMMING
}

\author{
Windra Tahir ${ }^{1 *}$, Djihad Wungguli ${ }^{2}$, Muhamad Rezky Friesta Payu ${ }^{4}$ \\ 1,2,3 Jurusan Matematika, Fakultas MIPA, Universitas Negeri Gorontalo, Bone Bolango 96119, Indonesia \\ *Penulis Korespondensi. Email: whindratahir@gmail.com
}

\begin{abstract}
Abstrak
Penjadwalan pekerja merupakan salah satu masalah yang dihadapi oleh setiap perusahaan. Peraturan yang ditetapkan perusahaan, ketersediaan banyaknya pekerja dan sistem pembagian kerja menjadi faktor penentu dalam sistem penjadwalan. Permasalahan penjadwalan pekerja ini dapat dimodelkan sebagai masalah Integer Programming. Integer Programming merupakan teknik optimasi dengan fungsi objektif linear, fungsi kendala linear dan variabel berupa bilangan bulat. Tulisan ini membahas formulasi masalah penjadwalan pekerja dalam bentuk Integer Programming dengan pekerja pada peruasahaan yang bergerak dalam produksi karet remah (Crumb Rubber) dengan fungsi objektif meminimumkan jumlah pekerja yang dipekerjakan. Model selanjutnya diimplementasikan menggunakan bantuan software LINGO 11.0. Hasil implementasi memperlihatkan bahwa model mampu menghasilkan jadwal pegawai yang optimal.
\end{abstract}

Kata Kunci: Integer Programming; Optimasi; Penjadwalan

\begin{abstract}
Scheduling workers is one of the problems faced by every company. The regulations set by the company, the availability of the number of workers, and the division of labor are the determining factors in the scheduling system. This worker scheduling problem can be modeled as an Integer Programming problem. Integer Programming is an optimization technique with linear objective functions, linear constraint functions, and integer variables. This paper discusses the formulation of worker scheduling problems in the form of Integer Programming with workers in companies engaged in the production of Crumb Rubber with the objective function of minimizing the number of workers employed. The next model is implemented using the help of LINGO 11.0 software. The implementation results show that the model is able to produce optimal employee schedules.
\end{abstract}

Keywords: Integer Programming; Optimization; Scheduling

\section{Pendahuluan}

Masalah optimasi penjadwalan dapat diklasifikasikan menjadi tiga jenis yaitu days-off scheduling, shift scheduling, dan tour scheduling [1]. Days-off scheduling adalah masalah penentuan hari kerja dan hari libur pekerja dalam waktu tertentu. Shift scheduling adalah penjadwalan yang berfokus pada interval waktu kerja dan libur pekerja, sedangkan tour scheduling merupakan kombinasi pola yang terbentuk dari days off Scheduling dan shift scheduling [2].

Penjadwalan hari kerja adalah masalah yang sering muncul pada sebuah perusahaan yang bekerja tujuh hari dalam seminggu. Oleh karena itu diperlukan penjadwalan yang jelas dan terperinci untuk setiap pekerja. Optimalnya suatu penjadwalan dapat meminimumkan tenaga kerja agar bisa menekan anggaran suatu perusahaan, sehingga biaya yang dikeluarkan untuk gaji pekerja dapat diminimumkan. Untuk meminimumkan biaya anggaran dibutuh penjadwalan yang optimal.

Pada umumnya penjadwalan di suatu perusahaan disusun secara manual oleh manager, sehingga tidak menutup kemungkinan adanya kesalahan dalam pembagian hari kerja untuk setiap pekerja. Hal ini mengakibatkan ada pekerja yang memperoleh hari kerja lebih banyak dari pekerja 
lain, ada juga yang memperoleh hari libur lebih banyak dari pekerja lain, serta adanya ketidakseimbangan ini dapat berpengaruh pada biaya yang harus dikeluarkan perusahaan pada setiap pekerja.

Penjadwalan hari kerja dapat diselesaikan dengan menggunakan beberapa metode yakni, metode simpleks Solusi Dual, Algoritma Monroe, Integer Programming dan metode-metode lainnya yang ada di pemograman linear. Penelitian menggunakan solusi dual dilakukan oleh Hadi [2] untuk mengoptimalkan penjadwalan tiga hari kerja dalam seminggu siklis. Dalam kasus tersebut diasumsikan setiap pekerja akan bekerja selama tiga hari kerja berturut-turut dan empat hari libur secara berurut dalam seminggu. Penelitian menggunakan Algoritma Monroe dilakukan oleh Syahputri, dkk [3] untuk menjadwalkan tenaga kerja dengan menentukan Regular Days Off (RDO) atau yang dikenal dengan hari libur untuk setiap pekerja. Dalam kasus tersebut diasumsikan setiap pekerja akan mendapatkan sepasang hari libur, serta melakukan minimalisasi biaya untuk tenaga kerja. Adapun penelitian yang menggunakan Integer Linear Programming dilakukan oleh Faatih [4] untuk menjadwalkan pegawai non operasional stasiun Depok. Dalam kasus ini diasumsikan setiap pegawai stasiun yang terpilih akan bekerja dalam dalam satu periode penjadwalan.

Adapun dalam penelitian ini, menggunakan Integer Programming untuk optimalisasi penjadwalan hari kerja, dengan asumsi adanya shift kerja serta hari libur untuk setiap pekerja. Disamping itu, jumlah hari kerja dan jumlah hari libur akan dibuat sama rata bagi setiap pekerja. Penelitian ini memiliki relevansi dengan penelitian Faatih [4], namun digunakan modifikasi model program yang berbeda yang akan melibatkan setiap pekerja dalam penentuan hari kerja, shift kerja dan hari libur dalam satu periode penjadwalan.

\section{Metode Penelitian}

Metode penelitian yang digunakan dalam penelitian ini adalah studi literatur, menggunakan data sekunder yang diperoleh dari hasil penelitian yang telah dipublikasikan. Data yang diperoleh diformulasikan dan diimplementasikan kedalam model Integer Programming untuk menemukan jadwal yang optimal.

\section{Hasil dan Pembahasan}

Formulasi model penjadwalan pada penelitian ini untuk menentukan antara lain pembagian shift antar pekerja, jumlah pekerja yang dibutuhkan, jumlah hari kerja dan hari libur pekerja. Pekerja yang akan dijadwalkan adalah pekerja disalah satu stasiun pada perusahaan yang bergerak dalam produksi karet remah (crumb rubber). Model yang dibuat ini bersifat umum sehingga dapat diimplementasikan permasalahan serupa, dengan ( $i$ ) yang merupakan banyaknya shift, dihari $(j)$ yang merupakan banyaknya hari dalam satu periode penjadwalan, untuk setiap $(k)$ yang merupakan banyaknya pekerja yang tersedia, $(s)$ adalah banyaknya pekerja yang dipenuhi untuk setiap shift, sedangkan $(h)$ adalah banyaknya hari kerja yang harus dipenuhi pekerja dalam satu periode penjadwalan. Berikut adalah aturan-aturan yang akan ditetapkan dalam penjadwalan ini:

a) Untuk setiap pekerja harus memenuhi jumlah pekerja yang dibutuhkan pada stasiun kerja disetiap harinya.

b) Untuk setiap pekerja hanya bekerja pada satu shift di setiap harinya.

c) Untuk setiap pekerja yang telah bekerja lima hari secara berturut-turut berhak mendapatkan hari dihari berikutnya.

\subsection{Model Penjadwalan}

Berdasarkan aturan tersebut model penjadwalan pekerja dapat diformulasikan sebagai berikut. 


\section{Himpunan dan Indeks}
I: Shift
$=1,2,3$
$\mathrm{J}:$ Hari $\quad=1,2, \ldots, 28$
$\mathrm{K}:$ Pekerja $\quad=1, \ldots, 20$

\section{Parameter}

$\mathrm{s}$ : Banyaknya pekerja yang harus terpenuhi untuk setiap shift.

$\mathrm{h}$ : Banyaknya hari kerja yang harus terpenuhi dalam satu periode penjadwalan.

\section{Variabel Keputusan}

$$
A_{i, j, k}= \begin{cases}1, & \text { jika pekerja k bekerja di hari } j \text { di shift i } \\ 0, & \text { jika pekerja } k \text { tidak bekerja di hari } j \text { di shift i }\end{cases}
$$

\section{Fungsi Objektif}

Fungsi objektif $\mathrm{z}$ dari penjadwalan hari kerja pekerja adalah meminimumkan banyaknya pekerja yang bekerja dalam satu periode penjadwalan. Fungsi objektif dari penjadwalan pekerja sebagai berikut:

$$
\operatorname{Min} Z=\sum_{i=1}^{3} \sum_{j=1}^{28} \sum_{k=1}^{20} A(i, j, k)
$$

\section{Kendala}

Kendala yang harus terpenuhi untuk penjadwalan ini adalah sebagai berikut:

1. Banyaknya pekerja stasiun yang bekerja setiap haridisetiap shift harus memenuhi kebutuhan. $\sum_{k=1}^{20} A_{i, j, k} \geq 7, \forall i=1,2, \forall j=1,2, \ldots, 28$

2. Untuk setiap pekerja stasiun hanya akan bekerja satu shift disetiap harinya. $\sum_{i=1}^{3} A_{i, j, k}=1, \forall j=1,2, \ldots, 28 \forall k=1,2, \ldots, 20$

3. Banyaknya hari kerja yang harus terpenuhi oleh setiap pekerja stasiun dalam satu periode. $\sum_{j=1}^{28}\left(A_{1, j, k}+A_{2, j, k}\right)=20, \forall k=1,2, \ldots, 20$

4. Untuk setiap pekerja staisun yang telah bekerja selama lima hari berturut-turut harus mendapat hari libur dihari berikutnya.

$$
\begin{aligned}
A_{1, j, k}+A_{2, j, k} & +A_{1, j+1, k}+A_{2, j+1, k}+A_{1, j+2, k}+A_{2, j+2, k}+A_{1, j+3, k}+A_{2, j+3, k}+A_{1, j+4, k} \\
& +A_{2, j+4, k}+A_{1, j+5, k}+A_{2, j+5, k} \leq 5, \forall j=1,2, \ldots(28-5), \forall k=1,2, \ldots, 20
\end{aligned}
$$

5. Semua variabel keputusan bernilai integer 0 atau 1 . $A_{i, j, k} \in(0,1), \forall i, j, k$.

\subsection{Jadwal Hari Kerja}

Masalah penjjadwalan hari kerja yang telah dimodelkan kemudian dimasukkan dalam proses komputasi menggunakan software LINGO 11.0. berdasarkan data masukan yang hasil optimum yang diperoleh dari meminimumkan jumlah pekeja sebanyak 20 pekerja akan disajikan pada Tabel 1 . 
Tabel 1. Skema jadwal optimal

\begin{tabular}{|c|c|c|c|c|c|c|c|c|c|c|c|c|c|c|c|c|c|c|c|c|c|c|}
\hline \multirow{2}{*}{ Hari $\mathrm{j}$} & \multicolumn{20}{|c|}{ Pekerja j } & \multirow{2}{*}{ TP } & \multirow{2}{*}{ Ts } \\
\hline & 1 & 2 & 3 & 4 & 5 & 6 & 7 & 8 & 9 & 10 & 11 & 12 & 13 & 14 & 15 & 16 & 17 & 18 & 19 & 20 & & \\
\hline 1 & $\mathrm{~L}$ & L & $s$ & P & $s$ & $\mathrm{~L}$ & L & P & P & $\mathrm{P}$ & $\mathrm{p}$ & $\mathrm{s}$ & $s$ & L & P & $s$ & $\mathrm{~L}$ & $\mathrm{~s}$ & $\mathrm{P}$ & $s$ & 7 & 7 \\
\hline 2 & $\mathrm{P}$ & $s$ & $\mathrm{~L}$ & $\mathrm{P}$ & $\mathrm{L}$ & $P$ & $s$ & $\mathrm{P}$ & $\mathrm{L}$ & $s$ & $\mathrm{~s}$ & $\mathrm{P}$ & $s$ & $\mathrm{~s}$ & $\mathrm{~L}$ & $\mathrm{~s}$ & $\mathrm{~L}$ & $\mathrm{P}$ & $\mathrm{P}$ & $\mathrm{L}$ & 7 & 7 \\
\hline 3 & $\mathrm{~s}$ & $\mathrm{p}$ & $P$ & $\mathrm{~s}$ & $\mathrm{~s}$ & $\mathrm{~L}$ & $\mathrm{~L}$ & $\mathrm{P}$ & $\mathrm{P}$ & $s$ & $\mathrm{p}$ & $\mathrm{s}$ & $P$ & $\mathrm{~s}$ & $\mathrm{~L}$ & $\mathrm{~L}$ & $\mathrm{~s}$ & $\mathrm{P}$ & $\mathrm{L}$ & $\mathrm{L}$ & 7 & 7 \\
\hline 4 & $\mathrm{~s}$ & $\mathrm{~L}$ & $P$ & $\mathrm{~L}$ & $\mathrm{~s}$ & $\mathrm{~s}$ & $\mathrm{~s}$ & $P$ & $\mathrm{~s}$ & $\mathrm{~L}$ & $\mathrm{p}$ & $P$ & $\mathrm{~L}$ & $\mathrm{~s}$ & $\mathrm{P}$ & $\mathrm{P}$ & $\mathrm{s}$ & $\mathrm{L}$ & $P$ & $\mathrm{~L}$ & 7 & 7 \\
\hline 5 & $\mathrm{~s}$ & $\mathrm{~L}$ & $s$ & $s$ & $\mathrm{~s}$ & $s$ & L & L & $P$ & $P$ & $\mathrm{P}$ & $\mathrm{L}$ & $P$ & $\mathrm{~L}$ & $s$ & L & $P$ & $s$ & $P$ & $P$ & 7 & 7 \\
\hline 6 & L & $\mathbf{p}$ & P & P & s & $P$ & P & $s$ & P & L. & L & $\mathrm{s}$ & $s$ & $\mathbf{P}$ & L. & L & $s$ & $s$ & $s$ & L & 7 & 7 \\
\hline 7 & $\mathrm{P}$ & $s$ & $\mathrm{~L}$ & $\mathrm{~L}$ & $\mathrm{~L}$ & $\mathrm{~s}$ & $\mathrm{P}$ & $\mathrm{P}$ & $\mathrm{L}$ & $\mathrm{L}$ & $\mathrm{P}$ & $\mathrm{s}$ & $\mathrm{P}$ & $s$ & $\mathrm{~s}$ & $\mathrm{~L}$ & $\mathrm{~s}$ & $\mathrm{P}$ & $\mathrm{s}$ & $\mathrm{P}$ & 7 & 7 \\
\hline 8 & $\mathrm{~s}$ & $\mathrm{~L}$ & $P$ & $\mathrm{P}$ & $\mathrm{s}$ & $\mathrm{L}$ & $s$ & $s$ & $\mathrm{P}$ & $\mathrm{L}$ & $\mathrm{P}$ & $\mathrm{s}$ & $\mathrm{P}$ & $\mathrm{s}$ & $s$ & $\mathrm{P}$ & $\mathrm{L}$ & $\mathrm{L}$ & $\mathrm{L}$ & $\mathrm{P}$ & 7 & 7 \\
\hline 9 & $\mathrm{~s}$ & P & $P$ & $\mathrm{~L}$ & $\mathrm{~L}$ & $\mathrm{~s}$ & $P$ & $s$ & $\mathrm{~L}$ & $s$ & $\mathrm{p}$ & $\mathrm{s}$ & L & $\mathrm{p}$ & $P$ & $\mathrm{~s}$ & L. & $\mathrm{s}$ & $\mathrm{L}$ & $P$ & 7 & 7 \\
\hline 10 & $\mathrm{~s}$ & $\mathrm{p}$ & $\mathrm{P}$ & $\mathrm{L}$ & $\mathrm{s}$ & $\mathrm{s}$ & $\mathrm{L}$ & $\mathrm{L}$ & $\mathrm{L}$ & $\mathrm{P}$ & $\mathrm{p}$ & $\mathrm{s}$ & $s$ & $\mathrm{~L}$ & $\mathrm{P}$ & $\mathrm{p}$ & $\mathrm{L}$ & $\mathrm{P}$ & $\mathrm{s}$ & $s$ & 7 & 7 \\
\hline 11 & $P$ & $s$ & $s$ & L & $\mathrm{L}$ & $P$ & $s$ & $\mathrm{~s}$ & $s$ & $s$ & $\mathrm{~L}$ & L & P & $\mathrm{P}$ & $\mathrm{P}$ & s & P & P & $\mathrm{L}$ & $\mathrm{L}$ & 7 & 7 \\
\hline 12 & $\mathrm{~L}$ & $s$ & $\mathrm{~L}$ & $\mathrm{P}$ & $\mathrm{P}$ & $\mathrm{s}$ & $s$ & $s$ & $s$ & $s$ & $\mathrm{P}$ & $\mathrm{s}$ & $\mathrm{P}$ & $\mathrm{p}$ & $\mathrm{L}$ & $\mathrm{p}$ & $s$ & $\mathrm{P}$ & $\mathrm{L}$ & $\mathrm{L}$ & 7 & 8 \\
\hline 13 & $P$ & L & P & $\mathrm{s}$ & $s$ & $P$ & $P$ & L & $s$ & $P$ & $\mathrm{~s}$ & $\mathrm{~s}$ & L & $s$ & $\mathrm{P}$ & L & $\mathrm{L}$ & $\mathrm{L}$ & $\mathrm{P}$ & $s$ & 7 & 7 \\
\hline 14 & $\mathrm{~L}$ & $\mathrm{P}$ & $\mathrm{L}$ & $s$ & $\mathrm{P}$ & $\mathrm{L}$ & $s$ & $s$ & $\mathrm{P}$ & $\mathrm{L}$ & $\mathrm{L}$ & $\mathrm{s}$ & $s$ & $\mathrm{~L}$ & $\mathrm{P}$ & $\mathrm{p}$ & $\mathrm{s}$ & $\mathrm{P}$ & $\mathrm{P}$ & $s$ & 7 & 7 \\
\hline 15 & $\mathrm{~s}$ & $s$ & $\mathrm{~L}$ & $s$ & $\mathrm{~s}$ & $\mathrm{~s}$ & $\mathrm{~L}$ & L & $\mathrm{s}$ & $P$ & $\mathrm{p}$ & $\mathrm{s}$ & $P$ & $\mathrm{~L}$ & $\mathrm{~L}$ & $\mathrm{P}$ & $P$ & $P$ & $\mathrm{~s}$ & $\mathrm{P}$ & 7 & 8 \\
\hline 16 & $\mathrm{~s}$ & $s$ & $\mathrm{~L}$ & $\mathrm{P}$ & $\mathrm{P}$ & $\mathrm{s}$ & $\mathrm{s}$ & $s$ & $\mathrm{~L}$ & $s$ & $\mathrm{~L}$ & $\mathrm{~L}$ & $\mathrm{P}$ & $\mathrm{P}$ & $\mathrm{P}$ & $\mathrm{P}$ & $\mathrm{L}$ & $\mathrm{L}$ & $\mathrm{P}$ & $s$ & 7 & 7 \\
\hline 17 & $\mathrm{~s}$ & p & $\mathrm{s}$ & $\mathrm{L}$ & $\mathrm{L}$ & $\mathrm{L}$ & $\mathrm{P}$ & $s$ & $s$ & $P$ & $\mathrm{~L}$ & $\mathrm{P}$ & $\mathrm{L}$ & $\mathrm{p}$ & $P$ & $\mathrm{~L}$ & $\mathrm{P}$ & $s$ & $\mathrm{~s}$ & $\mathrm{~s}$ & 7 & 7 \\
\hline 18 & L & $\mathbf{P}$ & $s$ & P & $s$ & L & $s$ & P & P & $\mathrm{s}$ & L & $\mathrm{P}$ & $\mathrm{P}$ & L & $\mathbf{s}$ & P & $\mathbf{s}$ & $s$ & L & L & 7 & 7 \\
\hline 19 & $\mathrm{P}$ & $\mathrm{L}$ & $\mathrm{L}$ & $\mathrm{P}$ & $\mathrm{P}$ & $\mathrm{s}$ & $\mathrm{P}$ & $s$ & $\mathrm{P}$ & $\mathrm{L}$ & $\mathrm{s}$ & $\mathrm{P}$ & $\mathrm{L}$ & $s$ & $s$ & $\mathrm{p}$ & $\mathrm{P}$ & $\mathrm{P}$ & $\mathrm{s}$ & $s$ & 9 & 7 \\
\hline 20 & $\mathrm{P}$ & $\mathrm{p}$ & $P$ & $\mathrm{P}$ & $\mathrm{P}$ & $s$ & $s$ & $\mathrm{~L}$ & $\mathrm{P}$ & $s$ & $\mathrm{~s}$ & $\mathrm{P}$ & $\mathrm{L}$ & $\mathrm{L}$ & $s$ & $\mathrm{~s}$ & $\mathrm{~L}$ & $\mathrm{~s}$ & $\mathrm{~L}$ & $s$ & 7 & 8 \\
\hline 21 & $\mathrm{P}$ & $\mathrm{s}$ & $\mathrm{P}$ & $\mathrm{P}$ & L & $P$ & $\mathrm{~L}$ & $s$ & $\mathrm{~L}$ & $\mathrm{P}$ & $\mathrm{P}$ & $\mathrm{s}$ & $\mathrm{L}$ & $\mathrm{s}$ & $\mathrm{L}$ & $\mathrm{s}$ & $\mathrm{P}$ & $\mathrm{P}$ & $\mathrm{s}$ & $s$ & 8 & 7 \\
\hline 22 & $\mathrm{~s}$ & $s$ & $\mathrm{P}$ & $\mathrm{P}$ & $\mathrm{L}$ & $\mathrm{L}$ & $\mathrm{s}$ & $s$ & $\mathrm{~L}$ & $s$ & $\mathrm{P}$ & $\mathrm{L}$ & $\mathrm{P}$ & $\mathrm{P}$ & $\mathrm{P}$ & $\mathrm{L}$ & $\mathrm{s}$ & $\mathrm{L}$ & $\mathrm{P}$ & $s$ & 7 & 7 \\
\hline 23 & $\mathrm{~s}$ & L & $s$ & L & $\mathrm{P}$ & $\mathrm{s}$ & $s$ & $\mathrm{~s}$ & P & P & $\mathrm{p}$ & L & P & s & P & P & $\mathrm{s}$ & $\mathrm{L}$ & $\mathrm{L}$ & $\mathrm{L}$ & 7 & 7 \\
\hline 24 & $\mathrm{~L}$ & $s$ & $\mathrm{P}$ & $\mathrm{s}$ & $\mathrm{P}$ & $\mathrm{s}$ & $\mathrm{L}$ & L & $\mathrm{P}$ & $s$ & $\mathrm{~L}$ & $\mathrm{~L}$ & $\mathrm{P}$ & $\mathrm{s}$ & $\mathrm{L}$ & $\mathrm{P}$ & $\mathrm{s}$ & $\mathrm{P}$ & $\mathrm{P}$ & $s$ & 7 & 7 \\
\hline 25 & $\mathrm{~L}$ & $\mathrm{p}$ & $\mathrm{L}$ & $\mathrm{P}$ & $s$ & $P$ & $\mathrm{~s}$ & $s$ & $\mathrm{~L}$ & $\mathrm{~L}$ & $\mathrm{~s}$ & $\mathrm{P}$ & $\mathrm{L}$ & $\mathrm{s}$ & $P$ & $\mathrm{~L}$ & $\mathrm{P}$ & $\mathrm{P}$ & $\mathrm{s}$ & $s$ & 7 & 7 \\
\hline 26 & $\mathrm{~L}$ & $\mathrm{p}$ & $\mathrm{P}$ & $\mathrm{P}$ & $\mathrm{s}$ & $\mathrm{s}$ & $\mathrm{s}$ & $P$ & $\mathrm{P}$ & $\mathrm{L}$ & $\mathrm{s}$ & $\mathrm{L}$ & $\mathrm{s}$ & $\mathrm{s}$ & $\mathrm{s}$ & $\mathrm{P}$ & $\mathrm{s}$ & $\mathrm{L}$ & $\mathrm{P}$ & $\mathrm{L}$ & 7 & 8 \\
\hline 27 & $\mathrm{P}$ & $\mathrm{P}$ & $s$ & $s$ & L & $\mathrm{L}$ & $\mathrm{P}$ & $\mathrm{L}$ & $\mathrm{s}$ & $s$ & $\mathrm{~L}$ & $\mathrm{~L}$ & $s$ & $\mathrm{~L}$ & $\mathrm{P}$ & $\mathrm{s}$ & $\mathrm{s}$ & $\mathrm{P}$ & $\mathrm{P}$ & $\mathrm{P}$ & 7 & 7 \\
\hline 28 & $\mathrm{~s}$ & L & $P$ & $\mathrm{~L}$ & $\mathrm{~s}$ & $\mathrm{P}$ & $\mathrm{L}$ & L & P & $s$ & $\mathrm{~s}$ & $\mathrm{P}$ & $s$ & $\mathrm{P}$ & $\mathrm{L}$ & $\mathrm{P}$ & $\mathrm{s}$ & L & $\mathrm{s}$ & P & 7 & 7 \\
\hline
\end{tabular}

Keterangan:

$\mathrm{P} \quad$ : shift pagi

$\mathrm{S} \quad$ : shift siang

L : libur

TP : jumlah pekerja yang bekerja pada shift pagi

TS : jumlah kekerja yang bekerja pada shift siang

Tabel 1 menunjukkan bahwa solusi yang diperoleh berupa jadwal optimal setelah diimplementasikan dengan model integer programming. Dalam hal ini, semua pekerja yang bekerja di stasiun pencincangan dan pembersihan yang telah dijadwalkan, dengan jumlah kebutuhan 7 pekerja disetiap shift dan jumlah pekerja tersedia sebanyak 20 pekerja. Memiliki 20 hari kerja untuk setiap pekerja dan 8 hari libur untuk setiap pekerja dengan bekerja hanya satu shift disetiap harinya serta tidak ada pekerja yang bekerja secara berturut-turut lebih dari 5 hari kerja.

\section{Kesimpulan}

Berdasarkan modifikasi model penjadwalan dengan menggunakan integer Programming untuk setiap pekerja stasiun yang bekerja memperoleh hasil berupa 20 hari kerja untuk setiap pekerja dan 8 
hari libur untuk setiap pekerja dengan hanya bekerja satu shift disetiap harinya, serta tidak ada pekerja yang bekerja secara berturut-turut lebih dari 5 hari kerja.

\section{Referensi}

[1] K.R Baker, "Workforce Allocation In Cyclical Scheduling Problem: A Survey Operational Research Quarterly," Jors, pp. 155-167, 2014.

[2] N. Hadi, “Optimasi Berbasis Dual Masalah Penjadwalan Tiga Hari Kerja Dalam Seminggu Secara Siklis", Institut Pertanian Bogor, 2014.

[3] K. Syahputri, L. Jelly, T.K. Devi, "Penjadwalan Tenaga Kerja Untuk Menentukan Regular Days Off(RDOs) dengan Menggunakan Algoritma Monroe," Media Teknika Jurnal Teknologi, pp. 10-16, 2017.

[4] I.A. Faatih, "Penjadwalan Pegawai Menggunakan Integer Linear Programming: Studi Kasus Pada Pegawai Non Operasional Stasiun Depok,” Institut Pertanian Bogor, 2018.

[5] D. G. Luenberger and Y. Ye, Linear And Nonlinear Programming, 3 Edition. California: Springer, 2007.

[6] H. K. Alfares, "Dual-Based Optimization Of Cylic Of Four-Day Workweek Scheduling,"IMA Journal OF Mathematic Applied In Bussines And Industry, vol. 2, no. 2, 2014.

[7] W. L. Winston, Operation Research Aplications And Algorithms, 4 Edition. New York: Duxbury, 2004. 